\section{Container Size Alters Root Growth of Western Black Cherry as Measured via Image Analysis}

\author{
Venu G. Oddiraju ${ }^{1}$ and Caula A. Beyl ${ }^{2}$ \\ Department of Plant and Soil Science, Alabama A\&M University, Normal, \\ AL 35762
}

\author{
Philip A. Barker ${ }^{3}$ \\ Service, Berkeley, $C A$ \\ Gary W. Stutte ${ }^{4}$ \\ Kennedy Space Center, Florida 32899
}

Pacific Southwest Research Station, U.S. Department of Agriculture Forest

Additional index words. root quantification, digitization, image processing

Abstract. Microcuttings of three western black cherry (Prunus serotina var. virens Ehrh.) phenotypes obtained from seedling trees with profuse or scant root systems were grown in two container sizes to examine the early effects of root constraint. Because manual methods to estimate root length and other characteristics are time consuming and subjective, an image analysis hardware and software system (image capture and analysis system) was used to classify and measure the roots. There was a significant effect of clone on fine-root surface area, coarse : fine root ratio, and root dry weight $(P \leq 0.05)$, but root characteristics (profuse or scant root development) of the parent material were absent in the vegetative propagules from these lines. Container size had no significant effect on coarse- or fine-root surface area but did reduce coarse : fine root ratio $(P \leq 0.05)$. A threshold effect of container size on root dry weight was detected $(P \leq 0.1)$.

Barker (1990) tested root constraints on container-grown western black cherry trees grown from seeds. That study involved 35and 70-cm-deep rootballs with and without plastic column rootball casings. Although he determined that the mean root weight under constraint was one-tenth of that without constraint, he also found a wide variation in the root weights, ranging from 20 to $1000 \mathrm{~g}$ in treatments without rootball casings. He attributed this variation to genetic factors because data analysis showed no noticeable environmental effect that could have caused such a variation. This variation offered the potential to select trees for their root development characteristics. One of our objectives was to use explants that were clonally propagated using material obtained from three of the original trees in Barker's study - two with profuse root systems ( $1 \mathrm{pr}$ and $4 \mathrm{pr}$ ) and one with a scant root system (8sr) - to determine the influence of these ortets (donor trees) on root characteristics of ramets (clones) in a constrained environment.

Although root restriction affects growth and development of many plant species, the importance of container volume has been ig-

Received for publication 23 Aug. 1993. Accepted for publication 1 Mar. 1994. The cost of publishing this paper was defrayed in part by the payment of page charges. Under postal regulations, this paper therefore must be hereby marked advertisement solely to indicate this fact.

${ }^{1}$ Graduate Research Assistant.

${ }^{2}$ Professor of Horticulture.

${ }^{3}$ Research Horticulturist.

${ }^{4}$ Plant Scientist. nored in many greenhouse and growth chamber studies (Carmi, 1986; Cooper, 1972). Richards and Rowe (1977) reported that plants grown in small containers characteristically develop shorter, more densely branched root systems than those grown in large containers. Also, in an experiment conducted on the influence of root-zone volume on tomato (Lycopersicon esculentum Mill.) growth and development, roots in small containers formed a highly branched mat, whereas those in large containers had long tap roots with little branching (Ruff et al., 1987). Because most such studies are not concluded until substantial root development and root mass overcrowding has occurred, a second objective in our study was to determine if differences in root development of the container-grown plants could be detected before the root mass was substantially overcrowded.

An image capture and analysis system (ICAS), which supports many special features for image analysis, such as instantaneous viewing and digital image capture (Stutte and Stutte, 1989), was used to quantify root surface areas of the plants under two levels of constraint. Using this system enabled us to classify roots as either fine or coarse and allowed us to differentiate which root type was more sensitive to root constraint-our third objective.

\section{Materials and Methods}

Procedures to develop tissue culture plantlets. Philip A. Barker provided buds from dormant, first-year wood from trees that had contrasting root systems in his 1988 experiment. He provided buds obtained from western black cherry trees characterized as having profuse root development [clone one, profuse
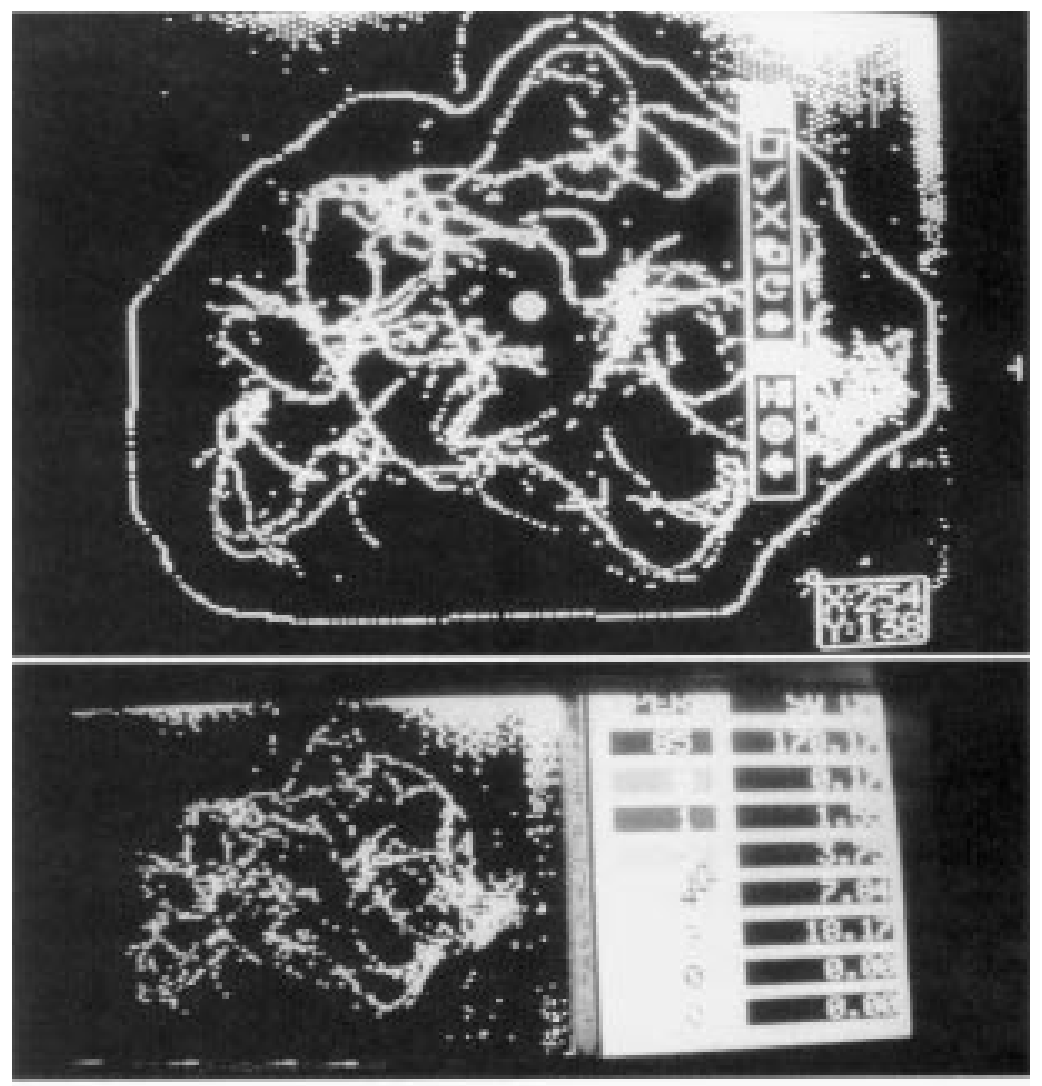

Fig. 1. Classified images using ICAS with area defined to perform an eight-level classification on (top) a root sample and percent pixels and (bottom) the area under each category displayed. 
roots (1pr) and clone four, profuse roots (4pr)] or scant root development [clone eight, scant roots (8sr)].

Buds collected from the three identified mature donor trees were sterilized following the procedure outlined by Tricoli et al. (1985). To establish the explants, initiation medium consisting of MS salts with (mg.liter $\left.{ }^{-1}\right) 0.4$ thiamine- $\mathrm{HCl}, 100$ myo-inositol, 1.0 benzylaminopurine (BA), 1.0 gibberellic acid $\left(\mathrm{GA}_{3}\right)$, and 0.1 indole-3-butyric acid (IBA) and $7 \mathrm{~g}$ Bacto-agar and $30 \mathrm{~g}$ sucrose/liter was used. The $\mathrm{pH}$ of the medium was adjusted to 5.7 with $\mathrm{NaOH}$ or $\mathrm{HCl}$; then $25 \times 150$-mm borosilicate glass tubes were filled with $25 \mathrm{ml}$ of the medium and covered with Kaputs $\mathrm{R}$ plastic caps. Explants were placed on the previously mentioned medium after it was autoclaved at $121 \mathrm{C}$ and $103.5 \mathrm{KPa}$ for $15 \mathrm{~min}$. Tubes containing medium and explants were placed in a growth room with a 16 -h photoperiod under fluorescent lights at $30 \mathrm{mmol} \cdot \mathrm{m}^{-2} \cdot \mathrm{s}^{-1}$ and a constant 26C.

After establishment on the initiation medium, explants were transferred to a multiplication medium to foster shoot proliferation. This medium contained full-strength MS salts with reduced levels of BA and IBA at 0.75 and $0.01 \mathrm{mg} \cdot$ liter $^{-1}$, respectively. The concentration of $\mathrm{GA}_{3}$ was $0.2 \mathrm{mg} \cdot \mathrm{liter}^{-1}$ and folic acid (0.001 mg.liter $\left.{ }^{-1}\right)$ was added. Sucrose and agar were kept at the same concentration as in the initiation medium. Shoots were subcultured every 4 to 6 weeks.

To encourage shoot elongation, shoots from multiplication medium were transferred to a hormone-free medium(MS0), which consisted of MS salts plus (mg.liter ${ }^{-1}$ ) nicotinic acid $(0.5)$, pyridoxine $\mathrm{HCl}(0.5)$, thiamine $\mathrm{HCl}$ (0.1), glycine (2.0), and myo-inositol (100) and sucrose $\left(30.0 \mathrm{~g} \cdot\right.$ liter $\left.^{-1}\right)$ and Bacto-agar $(7.0$ g.liter ${ }^{-1}$ )

Microcutting rooting and acclimatization. When the shoots had elongated to $\approx 5 \mathrm{~cm}$, the bottom portion of the stem was cut, and the stem was dipped in Hormex powder $(1.6 \%$ indolebutyric acid; Brooker Chemical, Hollywood, Calif.) before shoots were moved into plastic flats $(52.5 \times 26.25 \times 6.25 \mathrm{~cm})$ containing 72 starter pots $(3.75 \times 3.75 \times 5.9 \mathrm{~cm})$. Flats were filled with Promix BX (Premier Bands, Stamford, Conn.) that had been autoclaved and drenched well with 3a,4,7,7a-tetrahydro2-[(trichloromethyl)thiol]- $1 H$-isoindole1,3(2H)-dione (captan) solution (Microflo, Lakeland, Fla.) at $3.75 \mathrm{~g} \cdot$ liter $^{-1}$. Shoots were transferred into flats under a sterile transfer hood. Each rooting medium assembly consisted of three stacked flats, with a plastic liner between the second and third flats and a capillary mat between the first and second flats to maintain the required moisture. Plants were watered frequently to avoid desiccation. A transparent plastic cover was placed over the flat to cover the shoots, and the whole assembly was moved into a growth room. Cuttings were sprayed with $0.1 \mathrm{M} \mathrm{KNO}_{3}$ every other day for 2 weeks following their transfer. Cheesecloth was used to reduce the light intensities in the culture room to $40 \mathrm{mmol} \cdot \mathrm{m}^{-2}$ during the first week, after which it was removed; then

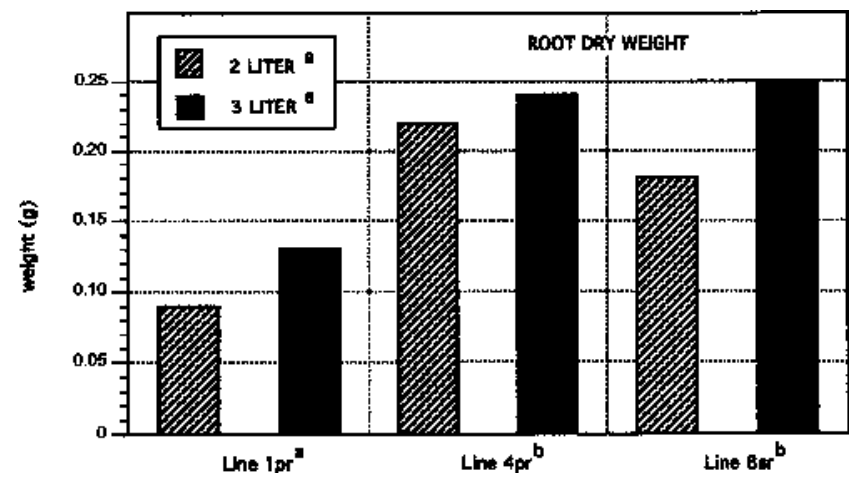

Fig. 2. Root dry weight of microcuttings of three western black cherry clones grown in two root restriction levels. Mean separation for lines and containers sizes at $P \leq 0.05$ by Tukey's HSD.

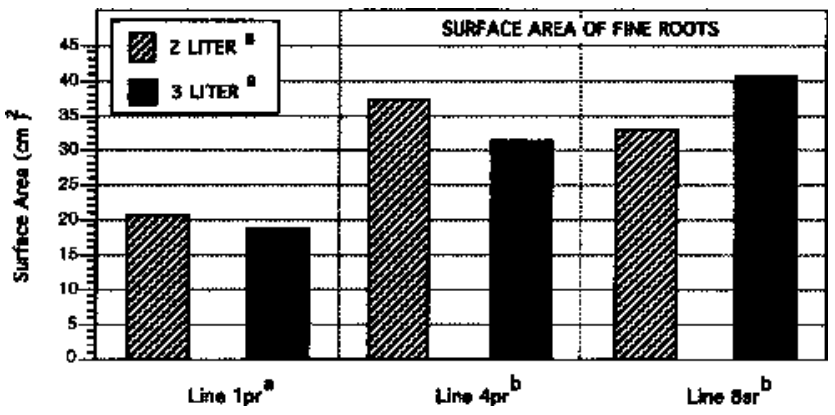

Fig. 3. Fine-root surface area of microcuttings of three western black cherry clones grown in two root restriction levels. Mean separation for lines and containers sizes at $P \leq 0.05$ by Tukey's HSD.

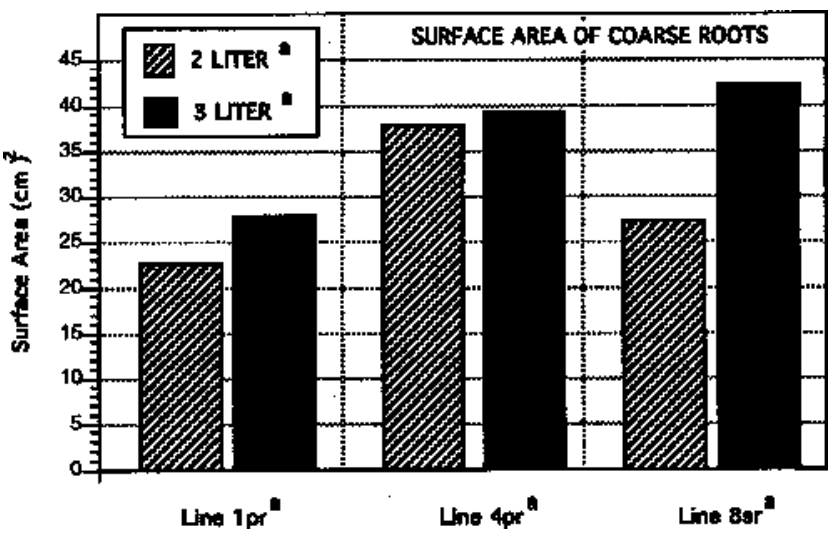

Fig. 4. Coarse-root surface area of microcuttings of three western black cherry clones grown in two root restriction levels. Mean separation for lines and containers sizes at $P \leq 0.05$ by Tukey's HSD.

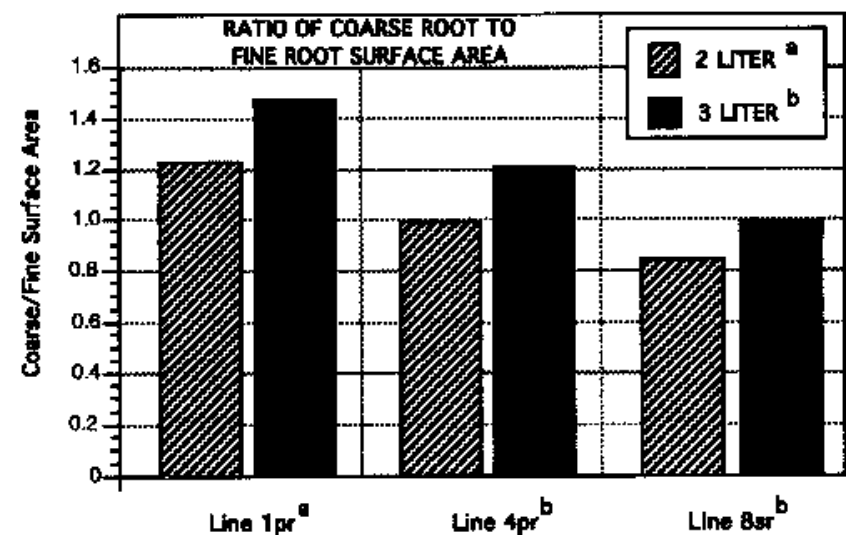

Fig. 5. Coarse : fine root ratio of microcuttings of three western black cherry clones grown in two root restriction levels. Mean separation for lines and containers sizes at $P \leq 0.05$ by Tukey's HSD. 
flats were exposed to higher light intensities at $\approx 200 \mathrm{mmol} \cdot \mathrm{m}^{-2} \cdot \mathrm{s}^{-1}$. The plastic cover was opened gradually starting on the third week. In the fourth week, the flats were moved to a greenhouse. Although the cover was left partially open, cheesecloth was used again to reduce high ambient light intensities.

Two weeks after the move to the greenhouse, the acclimatized plants of three ortets (one with scant roots and two with profuse roots) were moved into clear plastic containers containing Promix BX. The containers were made from clear, 2- and 3-liter, plastic soft drink bottles with the top $10 \mathrm{~cm}$ cut off. The clear containers permitted close observation of root growth and allowed us to easily detect when roots encountered the container bottoms. The experiment was arranged in a randomized complete-block design with a factorial arrangement of clones and containers and 15 replications per treatment.

Root surface area measurements. We ended the experiment in the 13th week, when roots in 3-liter containers had reached the side walls and were beginning to coil at the bottom of the container. The containers were lightly tapped and turned upside down to remove the rootball
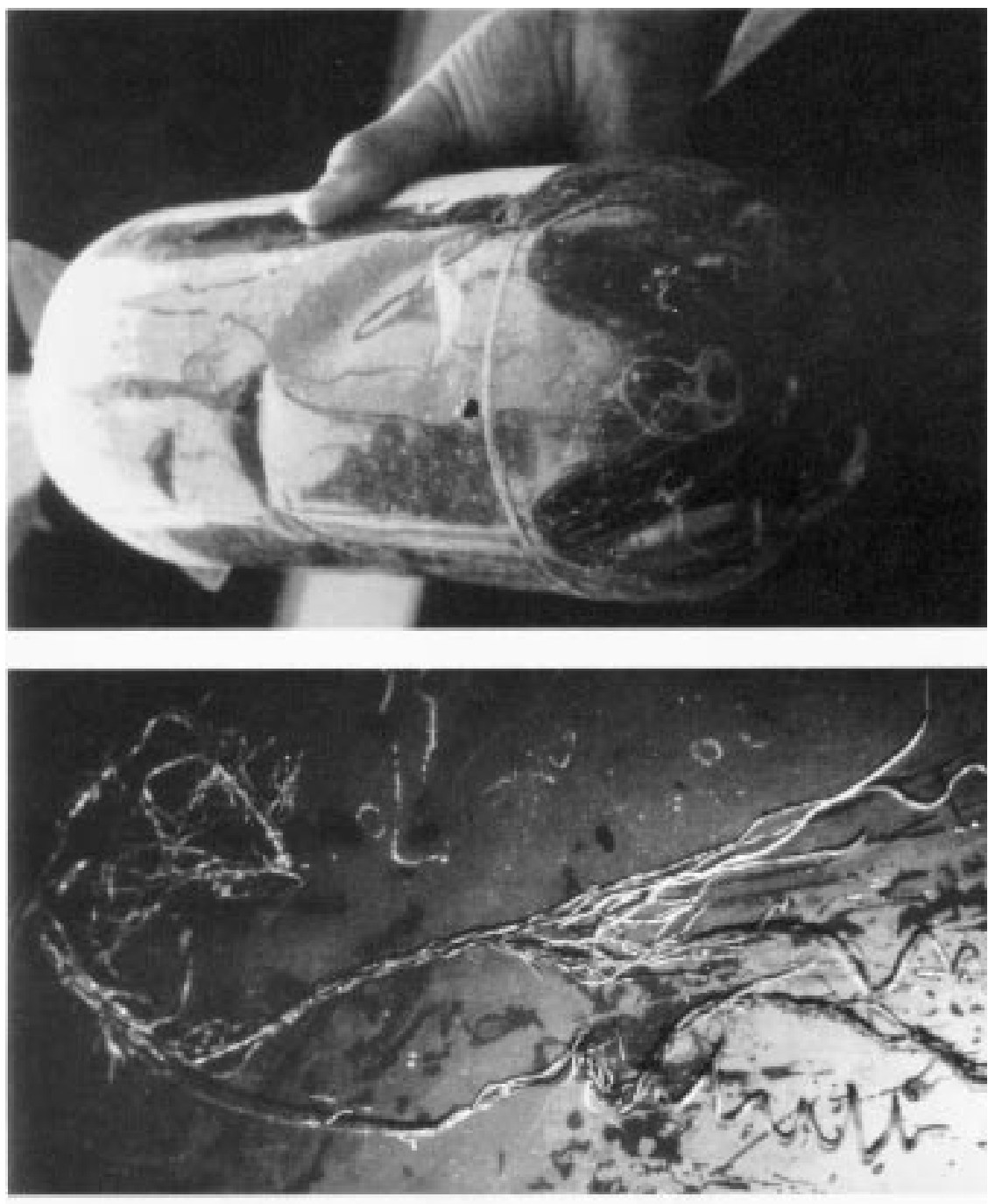

Fig. 6. (top) Roots of 'Chisos' western black cherry microcutting line 8sr showing roots coiling at the bottom of the 3-liter container and (bottom) line 4mr showing root appearance after being taken out of the 3liter container. intact. The soil was gently removed, and the roots were soaked in water overnight to help remove any residual adhering soil. Roots were washed thoroughly under running water before their surface area was measured.

ICAS (Digital Image Acquisition Systems, Englewood, Colo.) was used to measure the root surface area. Roots were placed on a fluorescent light box with the light directed on the roots at a $30^{\circ}$ angle using four $150-\mathrm{W}$ photoflood incandescent bulbs. Roots were digitized using a digital video camera and macro lens with autogain on low. The image setting was viewed on a video monitor that was in line with the ICAS digitization board to help focus the camera and position the roots. Images were digitized into $256 \times 256$ pixels by an ICAS digitization board that was supported by an IBM-compatible, 386, 25-MHz computer with a super VGA monitor.

Following digitization, background intensities were seleted from the image and an eight-level classification was performed on the untransformed digital image of the roots to obtain the percentage of each class of pixels and the area within each category (Fig. 1, top). Pixels with the lowest light reflectance inten- sity were placed into class 1 and those with the highest reflectance intensity into class 8 . By observing the intensities of light being reflected by different categories of roots, the eight-level classification was interpreted as classes 1 and 2 background; 3, 4, and 5 coarse roots; 6, 7, and 8 fine roots (Fig. 1, bottom).

\section{Results and Analysis}

An analysis of variance performed on the data showed a significant $(P \leq 0.05)$ effect of clone on the fine-root surface area, coarse : fine root ratio, and root dry weight and also a marginal effect $(P \leq 0.1)$ of clone on coarseroot surface area. The clones' rooting response had no relationship to the performance of the parent material from which the explants were obtained. Clone 1pr, which came from a tree that had profuse roots in the excavated zone (1174 g dry weight), had a significantly less profusely developed root system as measured by dry weight (Fig. 2) and fine-root surface area (Fig. 3), compared to clone 8sr, which originated from a scant-rooted selection with only $20.3 \mathrm{~g}$ dry weight of excavated roots. There was no significant difference between the performance of clone $4 \mathrm{pr}$ from a tree with profuse roots (886 $\mathrm{g}$ dry weight of excavated roots) and clone 8sr with respect to either dry weight or fine-root surface area. These trends were echoed in the coarse-root surface area (Fig. 4), although the differences were not significant $(P \leq 0.05)$.

\section{Discussion}

The differences in the root growth of the clones may have been confounded by differences in the quality of shoots used for microcuttings, although the selected shoots were initially uniform with respect to shoot length. Clone $1 \mathrm{pr}$ always performed poorly compared to other clones in the tissue culture environment, and its slow growth in the culture environment could have contributed to its poor performance. Wisniewski et al. (1986) reported that good initial quality caused improved growth of loblolly pine (Pinus taeda L.) plants derived from plantlets with highquality ratings, and poor plant growth was due to poor initial quality of the plantlets used. There was also a difference among clones with respect to the coarse : fine root ratio (Fig. 5), with clone $1 \mathrm{pr}$ having a significantly higher proportion of coarse roots than either $4 \mathrm{pr}$ or 8sr. Again, there was no relationship in clones from either profuse-rooted or scant-rooted ortets and their performance with respect to this characteristic. This experiment demonstrated that varying root characteristics of clonal parent material in terms of magnitude and root development pattern were not reproduced through bud explants clonally propagated and subjected to restricted container volumes.

Container size is thought to be important in long-term growth (Richards and Rowe, 1977), but to our knowledge, no one has documented when in the early development of a root system that container size plays a role. Although there was not a significant effect of container 
size on root dry weight at $P \leq 0.05$, it could be detected at $P \leq 0.10$. We ended our experiment only 3 weeks after roots in 3-liter containers started coiling at the container bottom (Fig. 6). Although this criterion for ending the experiment was good for detecting the time threshold necessary to perceive an incipient effect of root constraint, as in the case of dry weight, it may have been too early for all other effects of restricted root volume to appear. There was a significant effect $(P \leq 0.05)$ of container size on the coarse : fine root ratio, with relatively fewer coarse roots developing in the 2-liter than in the 3-liter size. It seems that container size has an influence on root developmen long before a root mass becomes potbound and overcrowded in a container.

\section{Literature Cited}

Barker, P.A. 1990. Tree root and sidewalk conflicts, p. 134-136. In: P.D. Rodbell (ed.). Make our cities safe for trees. Proc. Fourth Urban Forestry Conf., 15-19 Oct. 1989, St. Louis. Amer. For. Assn., Washington, D.C.

Carmi, A. 1986. Effects of root zone volume and plant density on the vegetative and reproductive development of cotton. Field Crop Res. 13:25-32.

Cooper, A.J. 1972. The influence of container volume, solution concentration, $\mathrm{pH}$ and aeration on dry matter partition by tomato plants in water culture. J. Hort. Sci. 47:341-347.

Richards, D. and R.N. Rowe. 1977. Effects of root restriction, root pruning and 6-benzylaminopurine on the growth of peach seedlings. Ann. Bot. 41:729-740.

Ruff, M.S., D.T. Krizek, R.M. Mirecki, and D.W.
Inouye. 1987. Restricted root zone volume: Influence on growth and development of tomato. J. Amer. Soc. Hort. Sci. 112:763-769.

Stutte, C.A. and G.W. Stutte. 1988. An interactive image capture and anlaysis system (ICAS) for research and crop management, p. 151-159. In: P. Mausel (ed.). Videography: First workshop. Amer. Soc. Photogrammetry and Remote Sensing, Terre Haute, Ind.

Tricoli, D.M., C.A. Maynard, and A.P. Drew. 1985. Tissue culture propagation of mature trees of Prunus serotina Ehrh. I. Establishment, multiplication and rooting in vitro. For. Sci. 31:201208.

Wisniewski, L.A., L.J. Frampton, Jr., and S.E. McKeand. 1986. Early shoot and root quality effects on nursery and field development of tissue-cultured loblolly pine. HortScience 21:1185-1186. 